\title{
Neutron Imaging of Advanced Transportation Technologies (ORNL)
}

\author{
Martin L. Wissink, Principal Investigator
}

Todd J. Toops, Charles E.A. Finney, Eric J. Nafziger, Derek Splitter, Hassina Bilheux

Oak Ridge National Laboratory

P.O. Box 2008

Oak Ridge, TN 37831

E-mail: wissinkml@ornl.gov

\section{Insert Name, DOE [Program/Technology Development] Manager}

U.S. Department of Energy

E-mail: [DOE [Program/Technology Development] Manager Email]

Start Date: October 1, 2016

Project Funding (FY18): \$282,000
End Date: September 30, 2018

DOE share: $\$ 282,000$
Non-DOE share: $\$ 0$

\section{Project Introduction}

Unlike X-rays, neutrons are very sensitive to light elements such as hydrogen $(\mathrm{H})$ atoms and can penetrate through thick layers of metals (Figure 1a). These two properties suggest neutrons are well suited to probe engine parts such as diesel particulate filters, exhaust gas recirculation coolers, fuel injectors, oil in engines, oil residues in filters, batteries, advanced materials, etc. Neutron imaging is based on the interactions of a sample with a neutron beam. The interactions are dependent on sample thickness/density and elemental make-up and result in absorption and scattering of neutrons within the sample. A two-dimensional position-sensitive detector placed behind the sample can measure the transmitted neutron flux (Figure 1b). When combined with a high-precision $(\sim 1 / 100$ of a degree) rotational stage, it is possible to perform computed tomography (CT) scans and thus generate 3-dimensional images of working fluids inside real devices. Samples can be analyzed at one position or a complete reconstruction can provide a cross-section of the entire sample at a resolution of the detector; the detector resolution is currently at $\sim 50-80$ microns (at the detector).

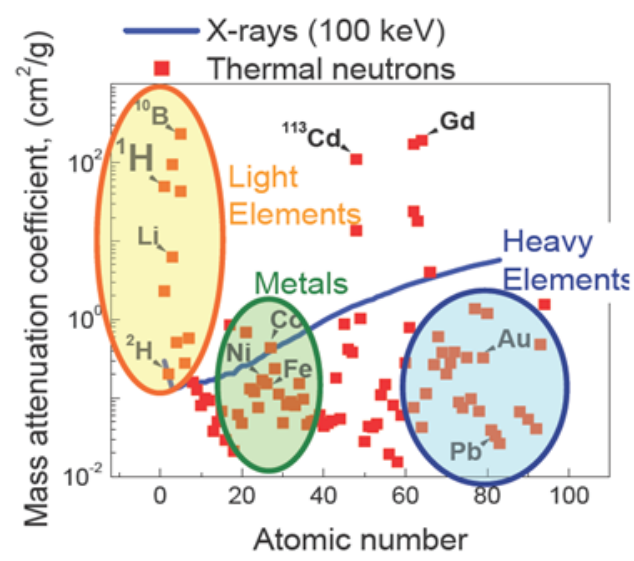

(a)

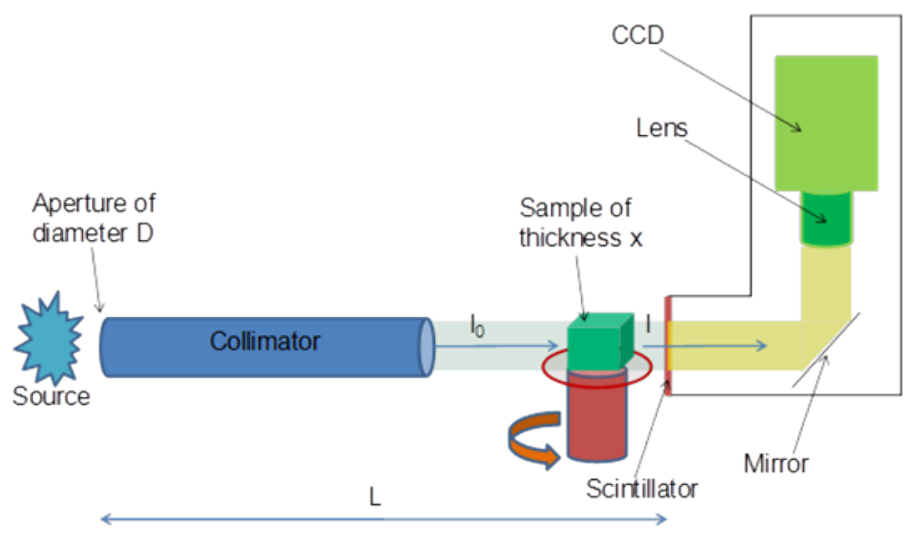

(b)

Figure 1. (a) Mass-attenuation coefficients with versus atomic number, and (b) schematic of neutron-imaging apparatus. (Source: (a) Nikolay Kardjilov (2006). (b) ORNL). 


\section{Objectives}

- Implement high-fidelity neutron imaging capabilities using the High Flux Isotope Reactor (HFIR) for advanced transportation research. Once fully developed, this advanced capability will allow the imaging of a range of processes that occur in advanced vehicle systems.

- Employ technique to aid improved design and control of complex advanced combustion systems and help to guide model validation and input.

- Report findings to research community and work with industrial partners to ensure research is focused on the most critical topics.

\section{Approach}

This project is focused on using this unique neutron imaging capability at ORNL's High Flux Isotope Reactor (HFIR) to advance the understanding of two components being employed in modern vehicles: the gasoline direct injector (GDI) and the particulate filter (PF). Recent efforts are aimed at investigating intra-nozzle fuel injector fluid dynamics while spraying. A specialized fuel delivery system and spray chamber are employed in this study that mesh well with the neutron beamline and GDI-style injectors (Figure 2). These efforts are designed to improve understanding of how injector design, external conditions, and fuel properties influence internal dynamics, especially as it relates to advanced combustion regimes and injector durability. PFs are a key component of the emissions control system for modern diesel engines, and possibly gasoline engines in the future, yet there remain significant questions about the basic behavior of the filters. In particular, understanding how ash, or non-regenerable metal oxide-based particulate, fills the PF and interacts with the wall is a focus of this effort. The results of these measurements will provide important data to the aftertreatment modeling community on the soot and ash profiles, which change over the course of the vehicle's lifetime. In carrying out these studies, we work closely with industrial partners to obtain relevant systems and devices. The proximity of our research facility to the neutron beam allows for iterative studies when appropriate.

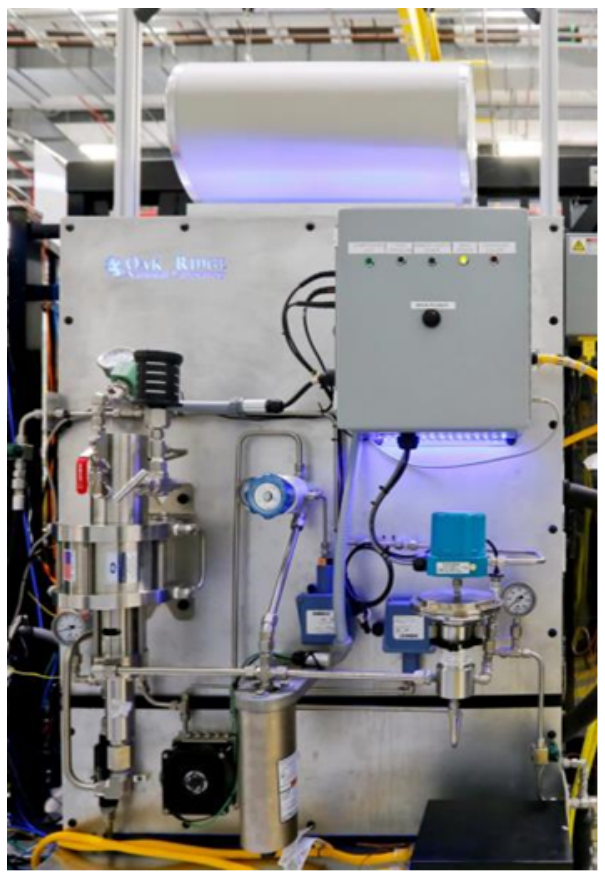

(a)

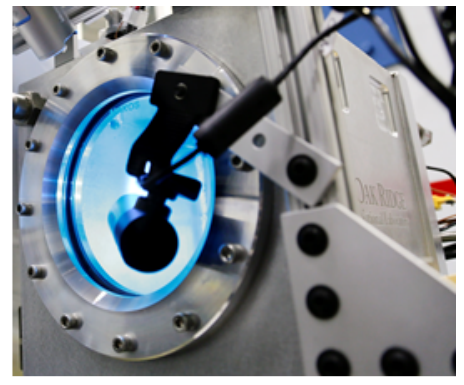

(b)

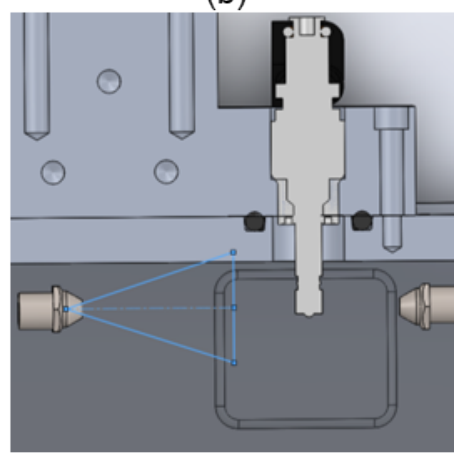

(c)

Figure 2. System used to study intra-nozzle dynamics of fuel injection include (a) high-pressure fuel delivery system and (b) the aluminum spray chamber with optical viewport. The spray chamber is designed with (c) directed fans to minimize fuel buildup on the chamber walls and the fuel injector. 
There has been collaboration with researchers from several institutions during this project, including Argonne National Laboratory, General Motors, Bosch, Continental Automotive, the University of Tennessee, the University of California, Berkeley, Boston University, and an MIT Consortium on PFs.

\section{Results}

The dynamic imaging effort has continued to focus on coordination with the Engine Combustion Network (ECN). This global community has set guidelines as to which baseline experimental conditions should be employed, and even goes as far as supplying injectors and other hardware. The experimental results can then be shared with the modeling community to help accelerate findings. While not part of the official collection of ECN injectors, General Motors has provided single-hole and 8-hole versions of the ECN Spray G, which is the common benchmark for GDI-style injectors. Bosch also donated a single-hole, large-bore injector which was used as part of a cavitation study with collaborators at Boston University. During the November 2017 neutron imaging campaign, all three of the injectors were operated using the ECN-preferred fuel, iso-octane, at operating conditions similar to the ECN-specified G2 and G3 conditions, including cases with both single and multiple injections. Neutron images were collected for each condition over 1-3 million injection cycles to produce an ensemble-average movie of the injection process.

The dynamic imaging analysis performed in FY18 focused on quantifying needle motion observed during and after injection, as shown in Figure 3 for the single-hole Spray G-style injector. Through the dynamic normalization approach, it is possible to see regions in the injector where the relative quantity of fuel varies from the static reference condition, as the fuel attenuates neutrons significantly more than the steel parts of the injector. This allows for visualization of the opening and closing of the check ball, as well as deflection or displacement of the needle both during and after injection based on the relative absence or abundance of fuel.

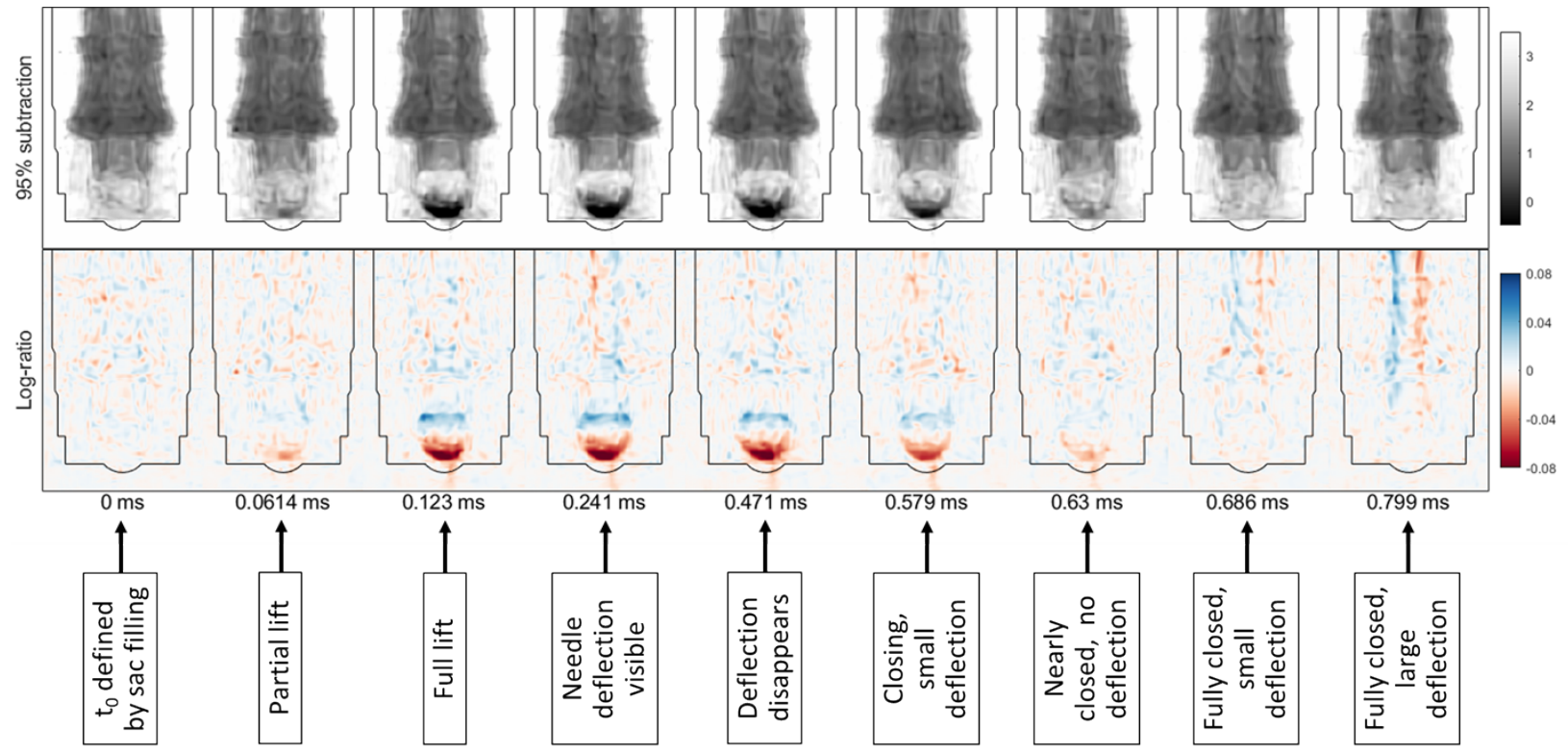

Figure 3. Normalized neutron radiographs of fuel injection from a single-hole GDI-style injector (ECN spray G) highlight ability to see opening and closing of the check ball as well as deflection of the injector both during and after injection. Top row shows subtraction-normalized images, which provide a qualitative understanding of the needle motion. Bottom row shows log-rationormalized images, which provide quantitative information on how the neutron path lengths change through the different materials during the needle motion. 
The quantification approach is based on modeling the neutron attenuation through the known geometry of the injector and how the neutron path length through the injector needle at a given pixel on the detector would change when the needle is displaced. This model is then fit to the normalized neutron imaging data by vertically averaging a region of the image with a strong indication of needle motion, as shown in Figure 4(a). This procedure is then performed for each image in the sequence, and the resulting model fits produce a result of displacement vs time over the averaged region, as shown in Figure 4(b). The model fit indicates oscillations during injection, as well as a large displacement immediately after the ball is seated at the end of injection, which agrees with the qualitative assessment from the normalized images. This analysis is being further refined to include the effects of detector blurring and needle location variation during the ensemble image collection, and a manuscript describing the approach and results is in preparation. Results to date have been shared with the ECN at the ECN 6 Workshop.

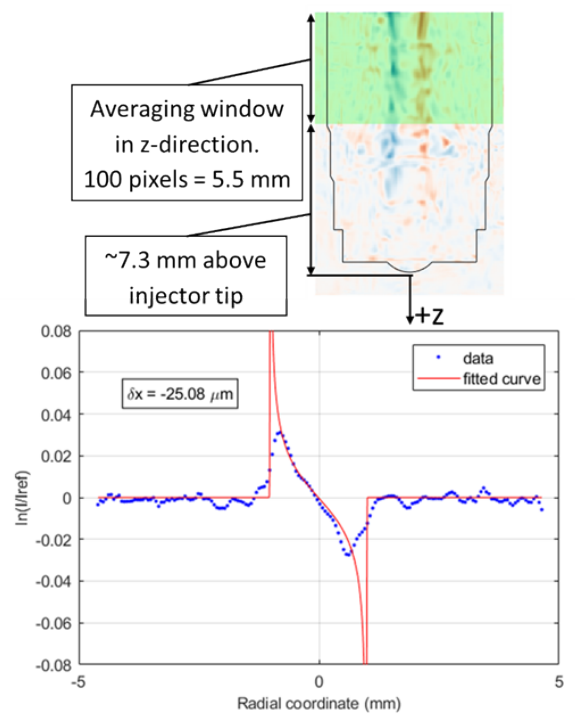

(a)

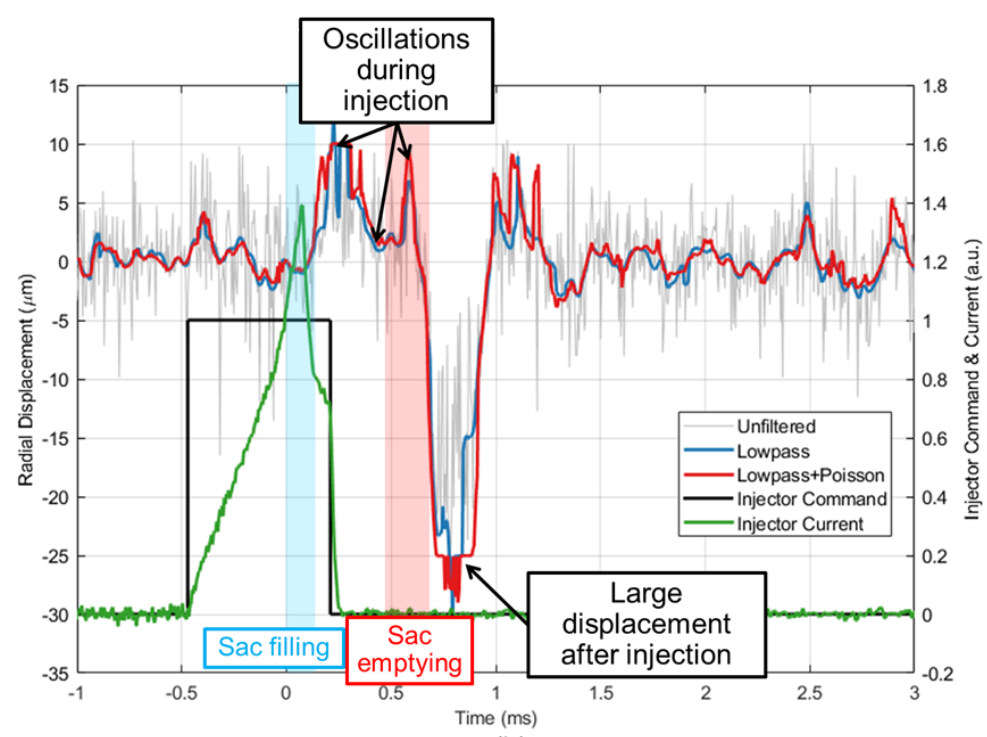

(b)

Figure 4. (a) Approach for fitting normalized image data to analytical path length model. (b) Needle displacement results show oscillation during injection and large movement after ball is seated. Results show low sensitivity to image filtering.

Other injector-related efforts in FY18 included performing a 2-part CT scan of the Bosch large-bore injector to obtain full internal flow geometry. As in previous FYs, collaboration continued with Argonne National Laboratory in which high-resolution x-ray CT was performed in the nozzle region, and neutron CT was performed on the entire geometry, which includes thicker metal features that are difficult to penetrate with $\mathrm{x}-$ rays. Figure 5 shows slices of the neutron CT of the injector, obtained at the High Flux Isotope Reactor at Oak Ridge National Laboratory, with an area surrounding the nozzle which was the focus of the high-resolution Xray CT, obtained at the Advanced Photon Source at Argonne National Laboratory.

Another area of focus continues to be particulate layers that are observed in gasoline particulate filters (GPFs). GPFs that were filled with particulate from a GDI-based engine using gasoline blended with $0 \%$ and $30 \%$ ethanol (E0 and E30, respectively) were imaged at HFIR using CT techniques. The GPFs were originally filled to $4 \mathrm{~g} / \mathrm{L}$ and then sequentially regenerated followed by imaging. In previous FYs, several imaging campaigns were performed for regeneration levels up to $80 \%$, and that work was concluded in FY18 by performing imaging at $100 \%$ regeneration. In contrast to the particulate layers typically seen in diesel particulate filters (DPFs), there is minimal decrease in thickness until $40 \%$ of the particulate is regenerated, as seen in Figure 6 for both E0 and E30. Differences between the E0 and E30 are also apparent, as the soot thickness decreased continuously as the E0 DPF was regenerated, whereas the soot cake thickness appeared to stall multiple times during the E0 DPF regeneration. 


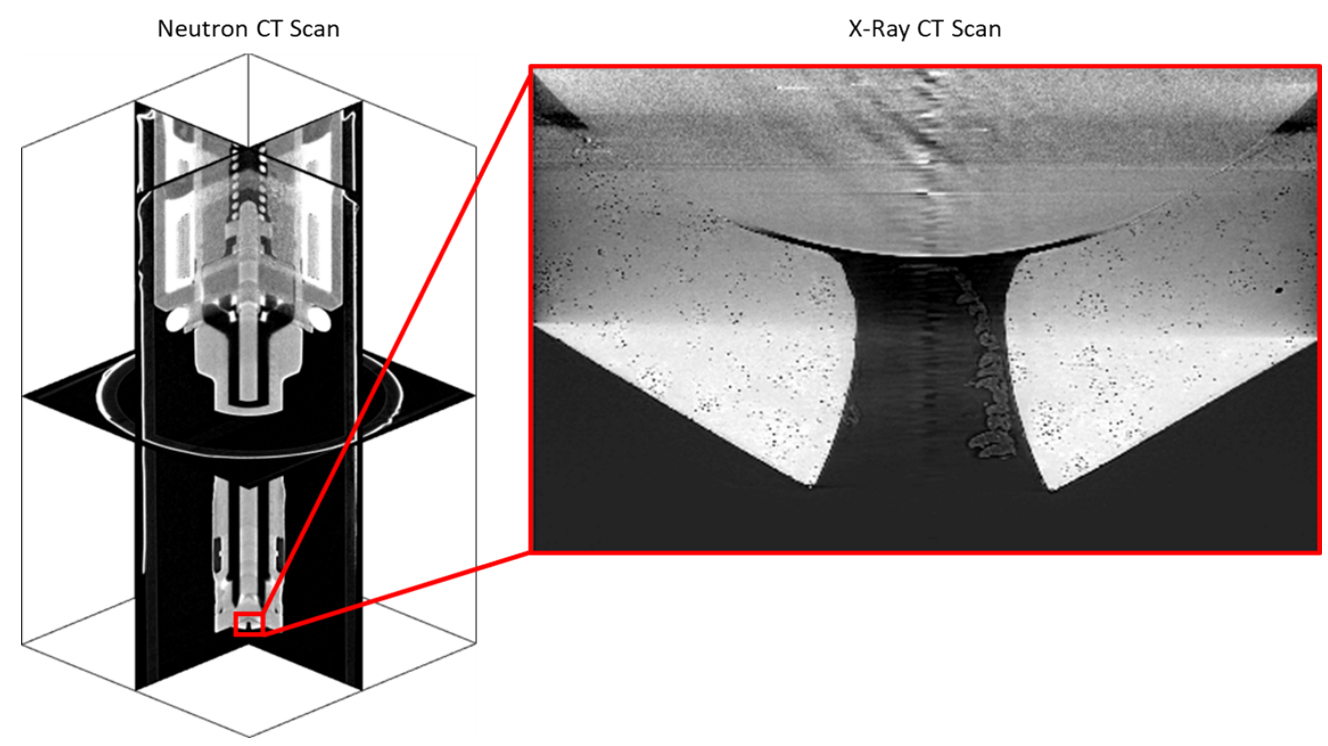

Figure 6. Slices of Neutron and X-Ray CT reconstructions of large-bore Bosch injector performed in collaboration with Argonne National Laboratory.
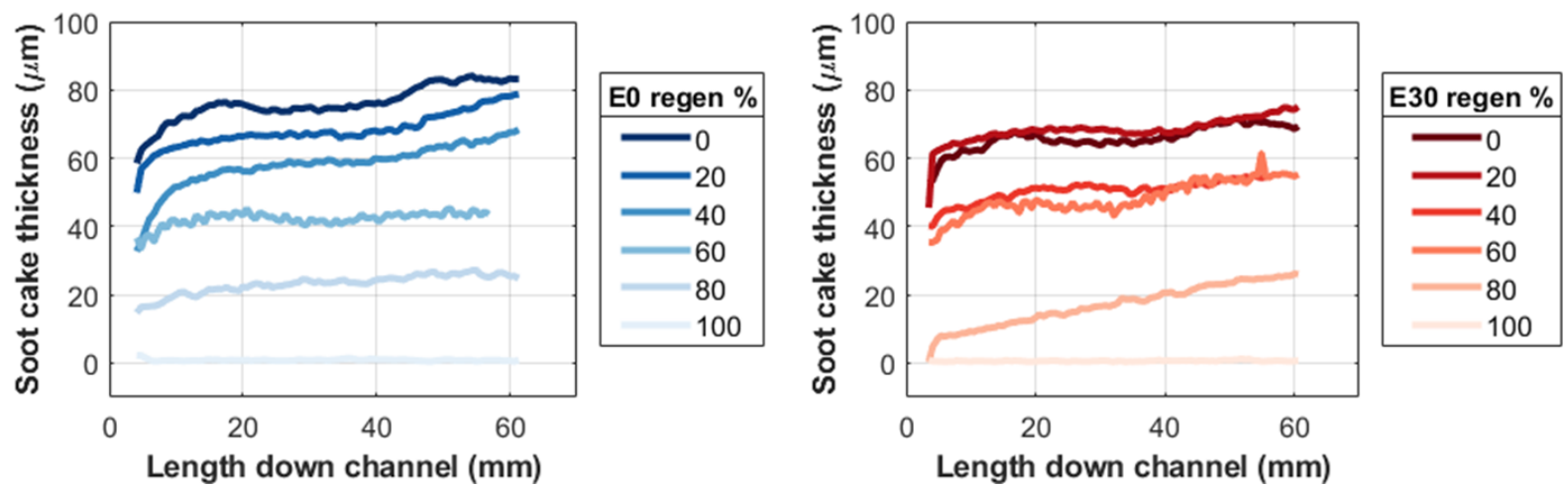

Figure 5. Soot cake thickness down GPF channel length extracted from neutron CT scans shows continuous decrease with regeneration \% with Eo PM (left) and staggered decrease with E30 PM (right).

\section{Conclusions}

Neutron imaging is a non-destructive, non-invasive diagnostic approach to improve understanding of advanced vehicle and combustion systems, targeting fuel economy improvements and durability. Efforts to date have focused on fuel injectors and particulate filters:

- Neutron imaging of fuel injection in a dynamic capacity has been demonstrated at the High Flux Isotope Reactor (HFIR) CG-1D imaging beamline and has shown the ability to both visualize and quantify the internal injector dynamics, including fluid motion and needle deflection/displacement. Dynamic imaging was performed with three injectors using iso-octane at multiple chamber conditions with both single and multiple injections. All injectors exhibited oscillation of the ball and needle during injection, with significant effects seen in cases with multiple injections.

- Continuing the ongoing collaboration with Argonne National Laboratory, a 2-part CT scan of the Bosch large-bore injector was completed using both $\mathrm{x}$-ray and neutron approaches to combine their complementary abilities to obtain well-defined internal geometry of these devices. 
- The imaging campaign for GPFs loaded with soot from E0 and E30 was completed at 100\% regeneration. Gasoline particulate differs in behavior from diesel particulate and also varies with the ethanol fraction in the gasoline. The successive regeneration and imaging strategy employed in this project is yielding unique insights not otherwise attainable with other methodologies.

Future directions could include the following:

- Publication of quantitative dynamic GDI imaging approach and results to date

- A beamtime award of 6 days on the HFIR CG-1D imaging beamline has been scheduled for November 2018. Efforts for this campaign will be focused on needle and fluid motions higher throughout the entire GDI-based injector, including interactions between the needle and the upper stops and solenoid armature. A new spray chamber has been designed and built to enable these measurements as well as operation as more extreme conditions and with higher throughput.

- A new detector is being developed to enable measurements with higher signal-to-noise ratio and improved resolution and data throughput. Commissioning is anticipated in FY19.

\section{Key Publications}

1. Wissink, Martin, Charles Finney, Eric Nafziger, Derek Splitter, and Todd Toops. "Internal GDI-based injector dynamics employing neutron radiography." Poster presented at THIESEL2018: Thermo and fluid dynamic processes in direct injection engines, Valencia, Spain, Sept 11-14, 2018.

2. Wissink, Martin, Todd Toops, Charles Finney, Derek Splitter, and Eric Nafziger. "Attenuation modeling approach to dynamic neutron imaging of gasoline direct injectors." Presentation at Engine Combustion Network ECN6 Workshop, Valencia, Spain, September 10, 2018.

3. Barnard, Richard C., Hassina Bilheux, Todd Toops, Eric Nafziger, Charles Finney, Derek Splitter, and Rick Archibald. "Total variation-based neutron computed tomography." Review of Scientific Instruments 89, no. 5 (2018): 053704.

4. Wissink, Martin, Todd Toops, Charles Finney, Eric Nafziger, Derek Splitter, and Jonathon Willocks. "Neutron Imaging of Advanced Transportation Technologies." Presentation at DOE VTO Annual Merit Review, June 19, 2018.

5. Wissink, Martin, Todd Toops, Charles Finney, Eric Nafziger, Derek Splitter, Hassina Bilheux, and Louis Santodonato. "An Update on Neutron Diagnostics of Transportation Technologies." Presentation at AEC Program Review Meeting, Argonne National Laboratory, Jan 31, 2018.

\section{Acknowledgements}

Tyler Ambrico contributed to the dynamic imaging analysis over the summer of FY18 as a part of DOE's Science Undergraduate Laboratory Internship (SULI) program.

This research used resources at the High Flux Isotope Reactor, which is a DOE Office of Science User Facility.

$\begin{array}{ll}\text { Acronyms, Abbreviations, Symbols, and Units } \\ \text { CT } & \begin{array}{l}\text { computed tomography } \\ \text { diesel particulate filter }\end{array} \\ \text { DPF } & \text { gasoline with } 0 \% \text { ethanol by volume } \\ \text { E0 } & \text { gasoline with } 30 \% \text { ethanol by volume } \\ \text { E30 } & \text { Engine Combustion Network } \\ \text { ECN } & \text { gasoline direct injector } \\ \text { GDI } & \text { gasoline particulate filter } \\ \text { GPF } & \text { High Flux Isotope Reactor } \\ \text { HFIR } & \text { Oak Ridge National Laboratory } \\ \text { ORNL } & \text { particulate filter }\end{array}$

